\title{
An importance-competence analysis of the roles and competencies of e-tutors at an open distance learning institution
}

\author{
Nadine de Metz, Adele Bezuidenhout \\ University of South Africa
}

\begin{abstract}
This study investigates the role of the e-tutor within an open distance learning (ODL) higher education institution in terms of perceptions of the work roles and assessment of the competencies of the e-tutor. As part of the universities' strategic plan the importance of providing excellent service to learners is strongly emphasised. E-tutors are the learner's first and foremost contact with the university; they invariably become the face of the ODL university for the geographically distant learner. E-tutors are therefore strategically important for the perceived quality and attractiveness of the university, however, they can also be a vulnerable link in the university's educational chain. The process of online tutoring therefore becomes a critical success factor in learners' acceptance of e-learning. The first phase of this research focuses on the e-tutor's perspective, investigating the competencies required by etutors to function effectively in an online environment, as well as their perceived role. A survey was administered to e-tutors in the College of Economic and Management Sciences of the university to assess their perceived roles and competencies. Understanding the importance of these roles and identifying necessary tutoring skills is paramount for the success of e-learning solutions.
\end{abstract}

\section{Introduction}

Over the years, open distance learning (ODL) institutions have experimented with many different technologies in their teaching and learning, in an attempt to find the best support for distance education students (Makoe, 2011). Along with the demands of mass higher education and an increasingly diverse student body with a broader range of needs, there has been an increased awareness of the role of the online tutor in higher education (Chang, Shen, \& Liu, 2014; Jelfs, Richardson, \& Price, 2009). Williams (2002) highlights the crucial role of the tutor with regards to the success of any form of computer-mediated communication. These new technological advancements through the introduction of networked technologies and virtual learning environments have a profound effect on the interaction of the learner with the institution and the learning environment. This consequently transforms the role of the tutor (Baumann, Shelley, Murphy, \& White, 2008).

Understanding the importance of these roles and identifying necessary tutoring skills is paramount for the success of e-learning solutions (McPherson \& Nunes, 2004). The unique role of the e-tutor requires continual reappraisal in an environment where technology change is constant (Cox, Clark, Heath, \& Plumpton, 2000), and in the midst of all these changes, it is still necessary to ensure that effective student learning takes place.

Despite the attempts in the literature to define distance tutor roles, little importance is assigned to the role of being a tutor at a distance (Baumann et al., 2008). Lentell and O’Rourke (2004) argue that tutoring as a professional activity has been carried out largely unseen and unanalysed. It is therefore seen as the less visible element of ODL, where tutors may be unheard or under-valued, but it is no less essential than good materials and effective administration (Lentell, 2003; Lentell \& O’Rourke 2004). Focus is often placed on developing information and communication technology (ICT)-based environments and insufficient attention is given to the delivery process. Therefore, insights into the changing role of the e-tutor and the competencies required in online learning environments (OLEs) need to be gathered to ensure that these environments are used in an optimum way (McShane, 2000). In order to deliver effective e-learning programmes it is crucial that online tutors understand their role and appreciate the demands of the online environment (Packham, Jones, Miller, \& Thomas, 2004). Chang et al. (2014) argue that despite the rapid increase in use of e-learning in higher education, the beliefs of e-tutors about their practices during online instruction rarely have been addressed. 
The focus of this study is on e-tutors within the biggest single college at a mega ODL University in South Africa. In the South African ODL universities' 2013-2015 strategic plan, the importance of providing excellent service to learners is strongly emphasised. E-tutors are the learner's first and foremost contact with the university; they invariably become the face of the ODL university to the geographically distant learner. E-tutors are therefore strategically important for the perception of the quality and attractiveness of the university but conversely can also be a vulnerable link in the university's educational chain. The majority of e-tutors at the ODL institution are new to online teaching and many of them do not have online learning experience upon which to draw. It is therefore essential to measure their level of competency and skills in order to identify professional training opportunities. Understanding what is lacking in online instruction is critical to help researchers and practitioners develop online support programmes for e-tutors in higher education (Chang et al., 2014). Since the tutors are often the only academic staff in direct contact with the students, their role perceptions and their relationships with the university are very important to the institution.

The contribution of this study can be distinguished from previous studies in that it employs an importancecompetence analysis to compare the importance of various e-tutor work roles with the perceived competence of the e-tutors to perform these roles effectively. It is accepted organisational practice that all employees are expected to fulfil certain predetermined, distinguishable work roles (Biddle, 1986), in this case the work role of the e-tutor. In order to perform any work role successfully, including that of an etutor, the individual needs to demonstrate certain specified competencies comprising skills, knowledge, and attitudes. Internationally, Varvel (2007) also highlights the importance of appropriate learning and development programmes, underpinned by relevant competency development for all distance educators. It follows logically that the e-tutor needs to perform these work roles competently in order to meet the expected quality of work standards and service delivery of the ODL university.

This paper reports part of the findings of a quantitative study focusing on the roles and competencies of etutors within a single college at an ODL institution in South Africa. The research presented here is part of a larger study conducted within the College of Economic and Management Sciences. The perceptions of etutors of their work roles, and the extent that they perceive they have the competencies needed to fulfil their work roles successfully, are deliberated in this paper. The study focused on three central research questions:

1. How do e-tutors perceive their work roles?

2. What specific competencies do e-tutors need to fulfil their work roles? and

3. To what extent do e-tutors perceive that they have the competencies needed to fulfil their work roles successfully?

\section{Literature review}

\section{The role of online tutors in distance education}

Significant changes have taken place in distance education, resulting in online delivery characterised by the use of virtual learning environments and various web technologies (Bates, 2008; Chang et al., 2014). Einstructors or e-tutors now play a very important role in these learning environments. However, while they play a crucial role in e-learning success, they face many new challenges in higher education (Goold, Coldwell, \& Craig, 2010). Rapidly evolving developments in e-learning raise the question of the roles required of online tutors, the skills and competencies that underpin these roles, and the need for training and professional development opportunities (Bennet \& Marsh, 2002). Packham, Cramphorn, and Miller (2001) argue that providers of these online courses face challenges in terms of recognition of effective teaching practice and student support. McPherson and Nunes (2004) explain that designing and delivering e-learning is not simply a matter of selecting a tutoring team with subject matter expertise and/or technical skills, but also involves choosing educationalists with the pedagogical, information, and communication skills that are required to manage and facilitate online learning. To be an effective tutor "it is clearly not enough to know which buttons to press in order to send an email or which HTML coding is required to insert an image on a web page” (Bennet \& Marsh, 2002, p. 14). Successful online learning depends on etutors acquiring new competencies, becoming aware of their potential and inspiring the learners instead of merely mastering the technology (Salmon, 2003). Thus, the choice of a suitable tutor team with appropriate skills is essential to successful online learning. 
Interacting in an online environment is very different from interacting in a face-to-face classroom (Denis, Watland, Pirotte, \& Verday, 2004; Goold et al., 2010). E-tutors require a paradigm shift in their perceptions of instructional time and space, virtual management techniques, and ways of engaging students through virtual communications (O’Neil, 2006). The range of these online activities and the multiple conditions of time, place significant technological demands on e-tutors, evidently more so than those associated with classroom teachers (Spector \& De la Teja, 2001). Perraton, Creed, and Robinson (2002) highlight the unique requirements of online e-tutors in effectively managing both the pedagogical and the logistical elements of instruction. These pedagogical elements include motivating students, promoting relevant learning, facilitating access to course content, engaging the learner in activities and discussions through communication, monitoring learners' progress, and adjusting learning opportunities to support learners in areas of difficulty (Gibson-Harman, Rodriguez, \& Haworth, 2002). From the above, it is clear that the online tutor undertakes a more complex role than that of traditional lecturers, and this requires a different set of skills and competencies.

In this article, the term $e$-tutor is used throughout the article and refers to the person most closely involved in the support of distance students at a specific college at the ODL institution. We adopt Denis et al.'s (2004, p. 3) definition and view the e-tutor as someone "who interacts directly with learners to support their learning process when they are separated from the tutor in time and place for some or all of these direct interactions". Other terms that are often used to describe this role are e-instructors (Chang et al., 2014), online teachers (Goodyear, Salmon, Spector, Steeples, \& Tickner, 2001), online moderator (Spector \& De la Teja, 2001), online instructors (Savory, 2005), distance education tutor, and online tutor. All these terms and definitions are used to refer to the same or similar roles.

The tutor role has been conceptualised in many different ways in the last two decades. Tait (2000), for example, defined the functions of student support as: (1) cognitive - supporting and developing learning through the mediation of the standard and uniform elements of course materials and learning resources for individual students; (2) affective - providing an environment which supports students, creates commitment, and enhances self-esteem; and (3) systemic - establishing administrative procedures and information management system which are effective, transparent, and student-friendly overall. As indicated by Baumann et al. (2008), here Tait does not make a direct reference to the role of tutors and their competencies and skills, however, he does lay the foundation for a further, more detailed definition of the tutor's role in distance learning. A more descriptive reference to the role of tutors is provided by Goodyear et al. (2001) when they identify eight main roles of an e-tutor: content facilitator, technologist, designer, manager/administrator, process facilitator, advisor/counsellor, assessor, and researcher. Denis et al. (2004), identify 11 online e-tutor roles that overlap to a great extent with Goodyear et al.'s (2001) roles. After a thorough literature search, it was decided to incorporate Denis et al.'s (2004) 11 main e-tutor roles. These roles are considered relevant in either a full distance or blended learning environment.

Brown (2002) argues that within the contemporary educational environment, different characteristics of roles may need to be combined to address specific e-learning contexts. It is recognised that one cannot generalise e-tutor roles as they might differ, depending on the unique e-learning context. There might also be overlap between different roles. In addition to identifying the necessary roles for the specific context, it is also necessary to investigate e-tutors' existing competencies and if there are any gaps in their competencies related to the roles they will be required to fulfil (Denis et al., 2004). The majority of e-tutors in this study were new to online teaching and were perhaps expected to "run before they can walk" (Bennet \& Marsh, 2002, p.15). There was therefore a need to investigate what their current competencies were compared to the roles they were expected to play.

\section{Context of the study}

The mega ODL university in this study is the largest ODL institution in South Africa and the only dedicated distance education university in South Africa. The university has high student enrolments associated with distance education (DE) as compared to residential universities (Mashile, 2012). Interaction is a crucial element of the university's student support conceptual framework. The view of the university is learnercentred, based on a socio-constructivist learning philosophy (Mashile, 2012). This means that they see learning as a result of several situated and dynamic connections between students and the curriculum, the resources which support the curriculum, lecturers and tutors, administrative and professional support 
functions offered by the institution, students' peers who are also studying for the same degrees, other peers, community members, and broader society (Open Distance Learning Task Team 4, 2010).

In its mandate as a comprehensive, ODL tertiary institution, the university introduced an online e-tutor service on an independent contract basis in 2013. The tutor model was part of an important strategy to improve the through-put rate and to provide students with the necessary academic and other support to obtain their qualifications within the requisite time periods (Mashile, 2012). The first cohorts of e-tutors were introduced to the ODL institution in February 2013. E-tutors were introduced only in 1st year modules in the 1st year of operation. The next cohort of e-tutors was introduced to the college in 2014 for the 2nd year modules. This study only focused on the e-tutors introduced at 1st year level modules as, at the time of the study, these e-tutors had been in operation for at least 1 year. A group of 200 students are linked to one e-tutor and students in a group are able to interact and learn from one another. Each e-tutor is expected to fulfil the following main duties (University of South Africa [Unisa], 2013):

- facilitate online delivery of tutorial material,

- manage students’ learning experiences online,

- facilitate students' interactions with their peers online, and

- $\quad$ provide students with academic and technical support online.

Within this study, the role of the e-tutor encompasses only asynchronous activities. The learner management system (LMS) used by the institution only allows for asynchronous communication, involving delayed communication between the learner and e-tutor within, for example, a discussion forum or question-and-answer application. The e-tutors are not permitted to communicate with students via e-mail or phone, as e-tutors need to communicate solely via the LMS with their students. The definition of etutoring for this study is therefore an organised session where students and e-tutors interact regularly online via the teaching and learning platform called myUnisa. Tools such as the discussion forum, announcement tools and additional resources tools are predominantly used to facilitate teaching and learning. The participation of students in tutoring is optional and tutorial activities do not contribute towards summative or formative assessment.

This is the first research study conducted at the ODL institution that focuses specifically on the skills and competencies of e-tutors employed on a contractual basis since the implementation of the new e-tutor system in the College of Economic and Management Sciences in 2013. There is a need to investigate their roles and competencies to ensure successful delivery of the different modules the e-tutors are responsible for, within an online environment.

\section{Research methodology}

In order to investigate the research questions on the e-tutor's expected roles and competencies, an empirical investigation was conducted. Permission was obtained from the university's ethics committee to conduct the study beforehand and care was taken to follow all protocols in terms of confidentiality, anonymity, and informed consent (Unisa, 2007). The study was conducted from a post-positivistic paradigm perspective (Baronov, 2012). The first stage of the research project entailed a non-experimental cross-sectional survey design, to determine the perceived roles and competencies of the e-tutors. The invitation to complete the online survey included an informed consent procedure. Once respondents proceeded to complete the electronic survey, data was imported directly into the Microsoft Excel computer programme. The data was checked for errors and cleaned before it was imported into the Statistical Package for the Social Sciences (SPSS). Initially, descriptive statistical analysis was performed on the data set in order to calculate measures of central tendency and dispersion of the data for every academic role identified.

\section{Population and sampling}

The target population for this study consisted of all e-tutors at the single largest college of the mega ODL university in South Africa. As the entire population consisted of 215 e-tutors, no sample was drawn and the entire population was invited to participate, hence a census method was employed. The study surveyed 215 e-tutors from seven different departments within the selected college. The questionnaire and cover letter were distributed to participants via an online survey. Confidentiality was guaranteed throughout the 
process. In total, 164 e-tutors completed the questionnaire. There were 65 questionnaires that were lacking some responses and these were eliminated, leaving 99 valid questionnaires. This left us with a valid response rate of $46 \%$. Demographic information collected included gender, highest qualification achieved, and which department within the College of Economic and Management Sciences the e-tutor belonged to. There was a fairly even distribution between males and females, with $44 \%$ e-tutors being female and 56\% male. Over half of the e-tutors (52.2\%) had a master's qualification, while $22.9 \%$ had doctoral degrees, $17.9 \%$ Baccalaureate degrees, and $7 \%$ honours or other degrees.

\section{Instrument}

Data was collected via an online questionnaire, comprising quantitative and qualitative questions. The questionnaire consisted of four parts, collecting data on: (a) demographic information, (b) perception of etutors' general work roles, (c) conceptions of effective tutoring, and (d) perceptions of e-tutor's central and peripheral roles and competencies. This article however only reports on sections (b) and (d) of the questionnaire.

The first part of the research was exploratory in nature and general work roles were identified using a combination of Berge's (1995) widely used classifications (where he categorised the conditions necessary for successful online instruction into four areas: pedagogical, social, managerial and technical), and Collins and Berge (1997) classification where they added additional roles to Berge's (1995) original list to include facilitator, administrator, promoter, and helper. In addition to their classification, the researchers found it necessary to include an additional role, the informative role, as these e-tutors were specifically assigned to 1st year students and play an important role in disseminating information to the first time students. It was also decided to use the term pastoral instead of promoter or helper. Thus seven roles in total were identified that were applicable to e-tutors functioning at 1st year level. The aim was to gain a better understanding of how e-tutors perceived their general work roles in terms of time spent on each role and which roles they perceived as important in their role as an e-tutor.

In the more descriptive part of the study, an importance-competence analysis was conducted. Lovelock, Patterson, and Walker (1998) initially proposed the use of an importance-performance analysis (IPA), as a useful management tool to direct scarce resources to areas where it is likely to have the biggest impact. Here it was necessary to identify more descriptive central and peripheral roles, to gain a better understanding of the perceptions towards the importance of each role and how competent they were in each descriptive role. The roles identified needed to be relevant in either a full distance or blended learning environment. The central and peripheral roles of e-tutors were defined using Denis et al.’s (2004) original 11 e-tutor roles, as these were the most applicable to the context of the specific learning environment and were relevant in both a full distance and blended learning environments. These roles are listed in Table 3 with an example of a statement describing each role. The question required the respondents to indicate their perceived level of importance, ranging from 1 (very important) to 5 (not important at all) for each item associated with each dimension as well as their current level of competency, ranging from 1 for (excellent) to 5 (not good at all) on a 5-point Likert scale. To enhance the validity of the instrument and the rigour of the research design, the instrument was pilot-tested with an experienced group of eight e-tutors and lecturers with online teaching experience at the selected college. They were asked to provide inputs and recommendations before the questionnaire was finalised, to improve the face validity of the instrument. Vague or ambiguous questions were identified and rephrased accordingly. Table 1 lists the central and peripheral e-tutor roles that were utilised for the study, and an example of a statement describing each role.

Three open-ended questions were also included in the questionnaire to allow for a deeper level of information sharing and analysis. Respondents were asked to discuss what factors impacted on their effectiveness as an e-tutor, what the barriers preventing them from being an effective e-tutor were, and whether they had any other comments regarding their experience of e-tutoring at the ODL University. 
Table 1

E-tutor roles

\begin{tabular}{|c|c|c|}
\hline E-tutor role & & Example of statement for each role \\
\hline \multirow[t]{7}{*}{ Central roles } & Content facilitator & I facilitate the learners understanding of the content. \\
\hline & $\begin{array}{l}\text { Metacognition } \\
\text { facilitator }\end{array}$ & I support reflection on learning activities and outcomes. \\
\hline & Technologist & $\begin{array}{l}\text { I make technological choices to improve the online } \\
\text { environment. }\end{array}$ \\
\hline & Process facilitator & I provide a welcoming online environment. \\
\hline & Assessor & I provide timely feedback. \\
\hline & Advisor & I provide students with advice on a one-to-one basis. \\
\hline & Resource provider & $\begin{array}{l}\text { I identify and locate, develop and produce resources to provide } \\
\text { "just in case" or "just in time" learning support. }\end{array}$ \\
\hline \multirow[t]{4}{*}{$\begin{array}{l}\text { Peripheral } \\
\text { roles }\end{array}$} & $\begin{array}{l}\text { Manager/ } \\
\text { administrator }\end{array}$ & I am involved in administration and record keeping. \\
\hline & Designer & I design worthwhile learning tasks. \\
\hline & Co-learner & $\begin{array}{l}\text { I see my role of e-tutor as "friend to the end" of the course, } \\
\text { walking with the learner-participant and learning alongside } \\
\text { them. }\end{array}$ \\
\hline & Researcher & $\begin{array}{l}\text { I am involved in the creation of new knowledge relevant to the } \\
\text { content. }\end{array}$ \\
\hline
\end{tabular}

\section{Research results}

The main aim and findings of this study revolve around the e-tutor's perceptions of their perceived roles and competencies, more specifically: how e-tutors perceived their general work roles in terms of time spent and perceived importance; what specific competencies do e-tutors need to fulfil their central and peripheral roles as e-tutors; and to what extent do e-tutors perceive that they have the competencies needed to fulfil these central and peripheral roles successfully. These findings have important implications for an improved understanding of the e-tutor's role within the ODL University.

\section{E-tutor roles perceived according to time spent and importance}

E-tutors were asked which roles demanded the most time and which roles demanded the least time in their job as an e-tutor. Seven roles were identified from the literature, namely: administrative, informative, managerial, pastoral, pedagogical, social, and technical. Respondents were asked to rank these roles according to the time spent $(1=$ most time spent and $7=$ least time spent $)$. Figure 1 illustrates the percentage of respondents who ranked the roles according to the time spent from most to least time. 


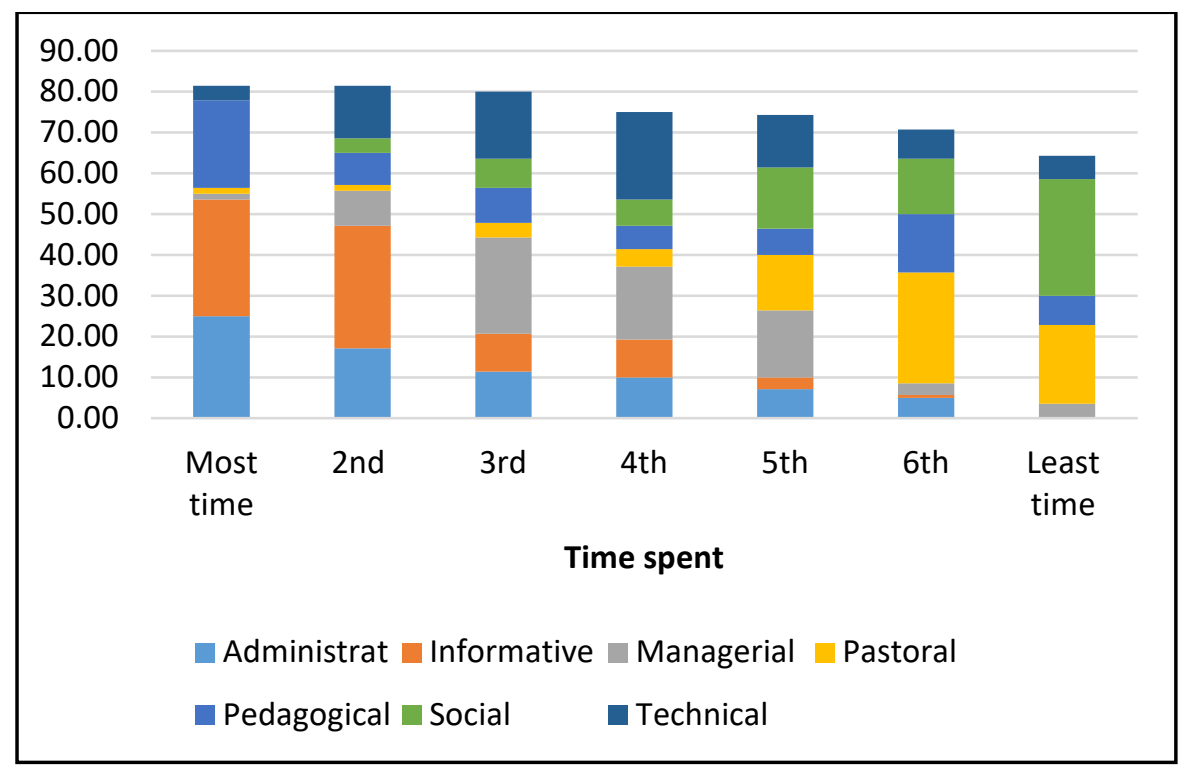

Figure 1. E-tutor perceptions of work roles according to time spent $(N=99)$

The results indicate that the highest percentage of respondents (28.57\%) ranked the informative role as the one they spent the most time on. This is not surprising, as 1st year students require a lot of information to orientate themselves and become familiar with the online environment. The second and third highest ranked roles in terms of most time spent were the administrative role (25\%) and the pedagogical role (21.43\%). Of concern was that e-tutors ranked the social (28.57\%) and pastoral roles (19.29\%) as the ones they spent the least amount of time on. The social role is one of the key critical success factors in online learning, as it involves the creation of a friendly and comfortable social environment in which students feel that learning is possible (McMann, 1994). In addition, tutors are often the first point of contact for students, especially when the students encounter difficulties in their learning process. The tutor therefore needs to provide pastoral care to guide students with these difficulties.

E-tutors were then asked which roles they perceived as most important and which roles they perceived as least important in their job as an e-tutor. Figure 2 illustrates the percentage of respondents who ranked the roles according to importance from most important to least important $(1=$ most important and $7=$ least important).

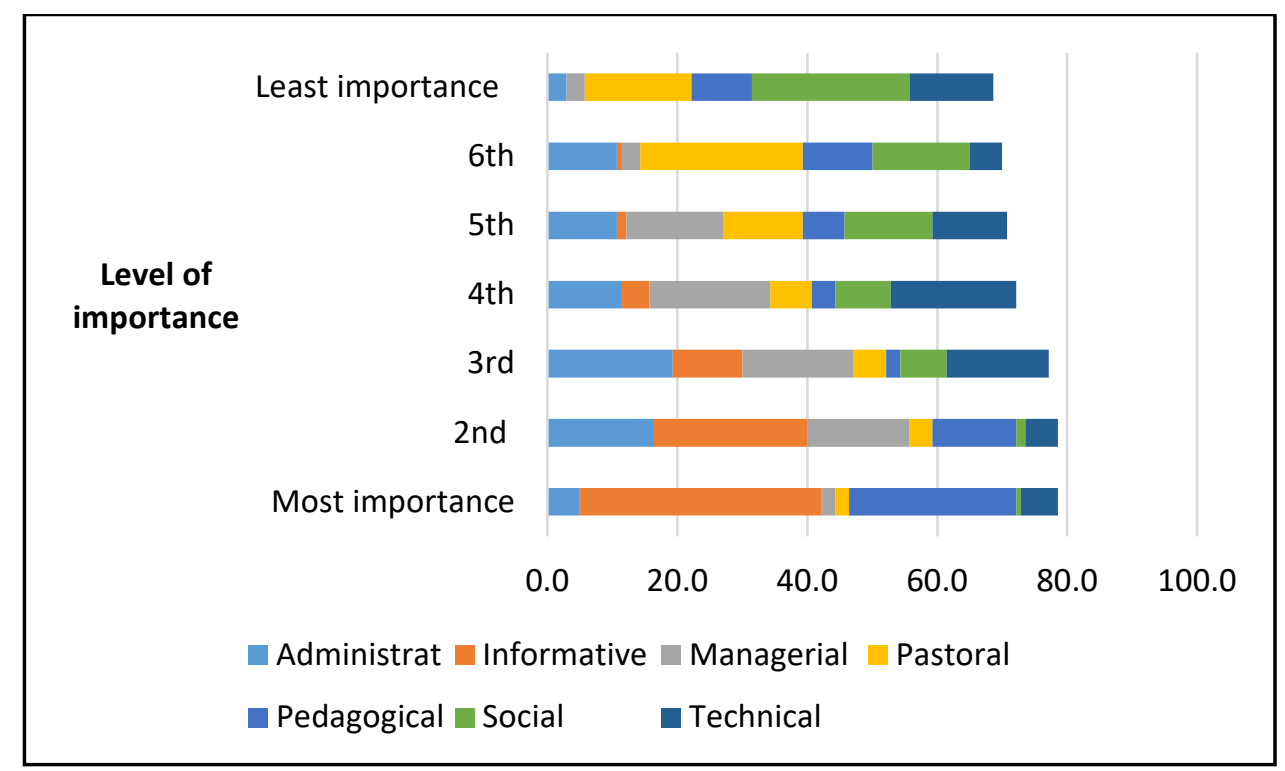

Figure 2. E-tutor perceived importance of work roles $(N=99)$ 
The results illustrate that the highest percentage of e-tutors (37.1\%) ranked the informative role as the most important. As previously mentioned, 1st year students require a lot of information initially in order to become orientated with the module and the online learning environment. It is therefore no surprise that the e-tutors ranked this role as the most important, in addition to ranking it as the one they spent the most time on. The pedagogical role was ranked as the second most important. A high percentage of e-tutors ranked the social (24.3\%) and pastoral (16.4\%) roles as the least important. This was rather surprising, as these two roles are important particularly for 1st year students, who need to get acquainted with the online environment and who need to gain confidence in their role as a student. Although only 5\% of the e-tutors ranked the administrative role as the most important; $25 \%$ of the e-tutors spent the most time fulfilling this role. The many administrative duties experienced by lecturers in permanent positions are typical of the academic environment and it was interesting to note that the e-tutors also felt they spent a lot of time fulfilling an administrative role. This is in line with previous research indicating that e-tutors spend considerable time on administrative work while they teach online courses (Chang et al., 2014). From the results, it is suggested that e-tutors should be spending more time fulfilling a social and pastoral role, and perhaps less time on the administrative role.

\section{E-tutors perceived roles versus their competencies}

A principal component analysis of e-tutor roles and competencies was conducted, using a VARIMAX rotation. The Kaiser-Meyer-Olkin Measure of Sampling Adequacy (0.818) and the Bartlett's Test of Sphericity, which was significant $(p=0.000)$, both indicate that a factor analysis is appropriate.

The analysis identified four factors, based on the eigenvalue criterion of eigenvalues greater than one, which explain $63.8 \%$ of the variance. The percentage variation explained was $38.3 \%, 11.1 \%$, $7.5 \%$, and $6.9 \%$ for the four factors respectively. The final factor loadings are shown in Table 3.

Table 2

Item descriptions and their factor loading value $(N=99)$

\begin{tabular}{clc}
\hline Item & Description of item and factor grouping & $\begin{array}{c}\text { Factor } \\
\text { loading } \\
\text { value }\end{array}$ \\
\hline 1 & Facilitating the learners understanding of the consent (Factor 1) & 0.776 \\
2 & Supporting reflection on learning activities and outcomes (Factor 1) & 0.707 \\
3 & Assisting learners in study skills development (Factor 2) & 0.554 \\
4 & Making technological choices to improve the online environment & 0.623 \\
5 & (Factor 2) & 0.714 \\
6 & Designing worthwhile learning tasks (Factor 2) & 0.798 \\
7 & Being involved in administration and record keeping (Factor 2) & 0.686 \\
8 & Providing a welcoming online environment (Factor 1) & 0.623 \\
9 & Managing communication and creating a community, in the online discussions & 0.635 \\
10 & (Factor 1) & Modelling of social online behaviour by establishing my own identity (Factor 3) \\
11 & Identifying and locate, develop and produce resources to provide “just-in-case” or & 0.790 \\
12 & “just-in-time” learning support (Factor 3) & 0.752 \\
13 & Providing students with advice on a one to one basis (Factor 4) & 0.746 \\
14 & I provide timely feedback (Factor 1) & 0.771 \\
\hline
\end{tabular}

Note. Factor descriptions: Factor 1 - social engagement; Factor 2 - administering the online environment; Factor 3 - developing/creating supporting material; Factor 4 - student feedback 
Upon further investigation of the four factors illustrated in Table 3, three of the factors were retained, namely factor one (social engagement), factor two (administering the online environment) and factor three (developing/creating supporting material) as these all had a number of item loadings higher than 0.5. Although factor four presented one fairly high loading (item 12), according to the literature (Tabachnick \& Fidell, 2007), one item is not sufficient to constitute a separate factor. To be labelled as a factor, there should be at least three items or variables that load on the factor. Based on the results of the principal component analysis, the reliability of each factor, specifically the Cronbach's alpha coefficient of each of the three factors retained, was calculated. The result for social engagement (factor 1) was 0.811; for administering the online environment (factor 2) was 0.750; and for developing supporting material (factor 3) was 0.797 . Thus, based on the statistical evidence, overall the survey proved to be highly reliable for all three retained factors. According to Field (2005), a reliability score of more than 0.8 may be appropriate for cognitive tests, 0.7 may be accepted for ability tests, and a Cronbach's alpha of 0.6 may be accepted for psychological tests.

\section{Paired $t$ tests}

In this study, a one sample $t$ test was conducted on the difference value between the importance rating of perceived e-tutor roles and the e-tutors' perception of their current level of competency in these roles. The null hypothesis tests if the mean value of the difference is equal to zero. According to Pallant (2013), if the value in the significance (2-tailed) column is equal to or less than $0.05(p=0.05)$, the difference between the importance rating of the perceived e-tutor roles and the e-tutors' perception of their current level of competency in these roles, is statistically significantly different from zero.

From the data gathered in Table 3, it appears that the e-tutors perceived a significant difference between the importance of specific work roles and how competent they felt in performing these roles. E-tutors perceived a significant difference in terms of items $1,2,3,4,5,7,9,11,14$, and item 15 as presented in Table 4.

Table 3

Paired sample test $(N=99)$

\begin{tabular}{cccccrcc}
\hline Item & $\boldsymbol{N}$ & $\boldsymbol{M}$ & $\boldsymbol{S E}$ & $\boldsymbol{t}$ & $\boldsymbol{d} \boldsymbol{f}$ & $\begin{array}{c}\text { Level of sig (2- } \\
\text { tailed) }\end{array}$ & $\begin{array}{c}\boldsymbol{M} \text { difference } \\
(\boldsymbol{D})\end{array}$ \\
\hline 1 & 101 & 0.3663 & 0.05755 & 6.366 & 100 & .000 & .36634 \\
2 & 99 & 0.2929 & 0.06300 & 4.650 & 98 & .000 & .29293 \\
3 & 100 & .4400 & 0.08327 & 5.284 & 99 & .000 & .44000 \\
4 & 100 & .3000 & 0.08933 & 3.358 & 99 & .001 & .30000 \\
5 & 101 & .2574 & 0.11574 & 2.224 & 100 & .028 & .25743 \\
6 & 100 & -0.100 & 0.12988 & -0.770 & 99 & .443 & -.10000 \\
7 & 100 & .1200 & 0.05556 & 2.224 & 99 & .033 & .12000 \\
8 & 99 & .1515 & 0.10488 & 1.445 & 98 & .152 & .15152 \\
9 & 100 & .2900 & 0.08077 & 3.590 & 99 & .001 & .29000 \\
10 & 100 & .2100 & 0.07426 & 2.828 & 99 & .006 & .21000 \\
11 & 100 & .3200 & 0.10238 & 3.126 & 99 & .002 & .32000 \\
12 & 100 & .1400 & 0.10251 & 1.366 & 99 & .175 & .14000 \\
13 & 99 & .1818 & 0.06318 & 2.878 & 98 & .005 & .18182 \\
14 & 100 & .1800 & 0.06094 & 2.954 & 99 & .004 & .18000 \\
15 & 100 & .4200 & 0.09968 & 4.214 & 99 & .000 & .42000 \\
\hline
\end{tabular}

Figure 3 further illustrates the gap between the importance of each specific work role and how competent e-tutors feel in performing these roles. When these findings are analysed in more depth, it is interesting to note that the e-tutors experienced quite a number of significant gaps between their actual competencies and the roles they are expected to fulfil. These gaps relate to facilitating the learners' understanding of the subject content (item 1), supporting learners’ reflection on learning activities and outcomes (item 2), assisting learners in developing study skills (metacognition) (item 3), making technological choices to improve the online environment (item 4), designing worthwhile learning tasks (item 5), providing a 
welcoming online environment (facilitating the process) (item 7), managing communication and creating online community in discussions (item 9), identifying, locating, developing and producing just-in-time learning support (item 11), being a friend-to-the-end, learning alongside learners (item 14), and creating new, relevant knowledge (item 15).

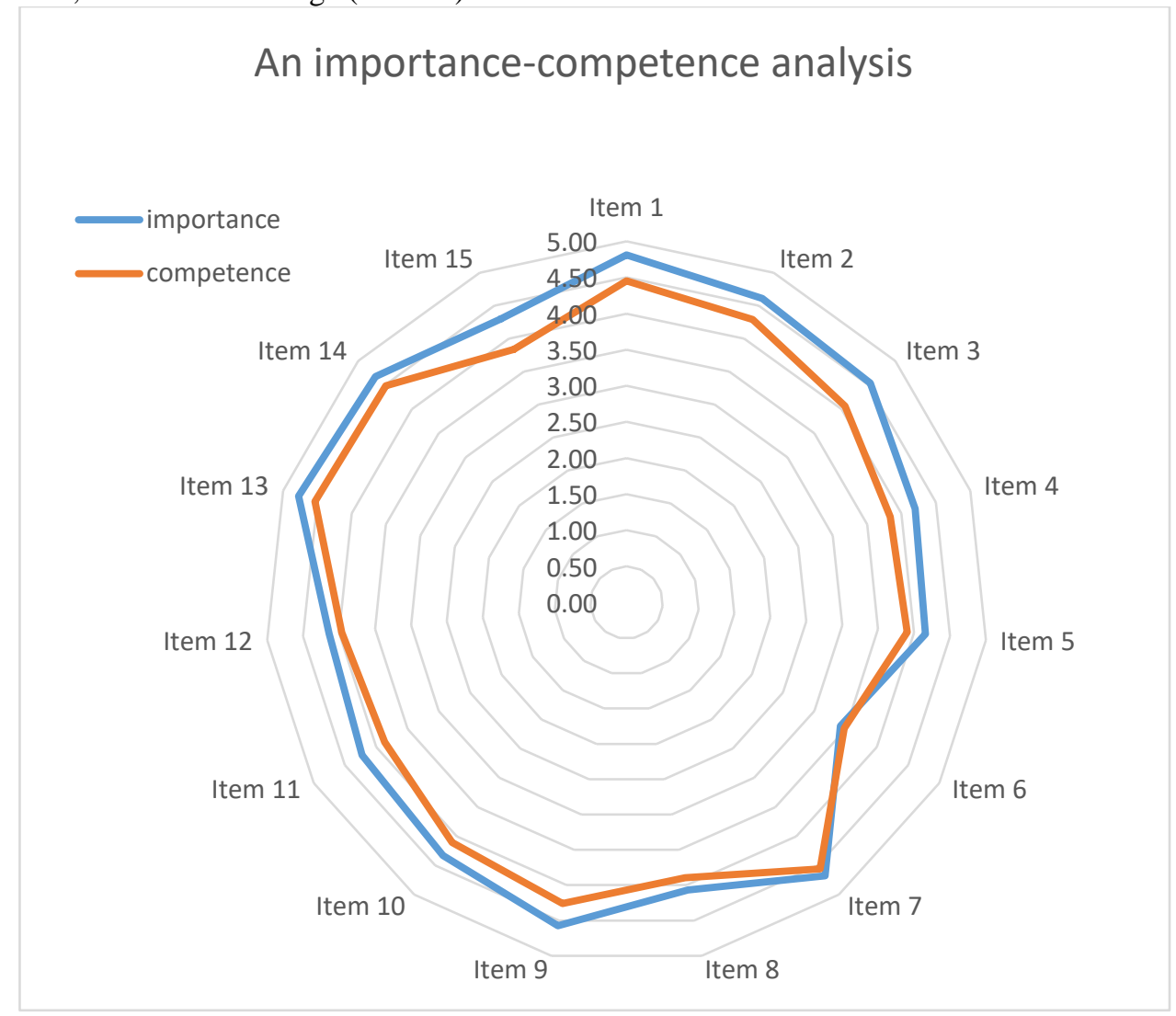

Figure 3. An importance-competence spider graph

The number of gaps identified representing the social engagement factor is noteworthy. It is evident that etutors perceive it a challenge to engage learners on the online forums. The distance learner's relative independence and lack of presence and interaction in the virtual environment may create a perception in etutors that they are failing in their efforts to support learners.

Conversely, e-tutors did not perceive a significant difference in terms of their roles and competencies on items $6,8,10,12$, and 13 ( $p \geq 0.05$ ). E-tutors thus did not perceive significant competency gaps in terms of managing, administration and record keeping, establishing ground rules, being an example of appropriate online social behaviour by establishing own identity, providing students with advice on a one-on-one basis and providing timely feedback. It is thus not recommended that training efforts focus on these competencies as a priority.

\section{Open-ended questions regarding effective e-tutoring from the e-tutor's perspective}

There were three open-ended questions at the end of the survey to gain further feedback from e-tutors regarding the factors impacting on their effectiveness as an e-tutor, the barriers preventing them from being effective e-tutors and any other comments regarding their experience of tutoring at the ODL University. Upon analysis, the following main themes emerged.

\section{Lack of participation}

The majority of e-tutors who responded to these questions indicated that a lack of participation by the students was an essential factor that impacted on their effectiveness as an e-tutor. One e-tutor commented: 
The student feedback is very important to me. If students do not provide feedback or respond to your posts, that impacts negatively on your effectiveness as an e-tutor.

Many e-tutors expressed their frustration at the lack of participation by students, despite their attempts to get students involved:

Out of 200 students there is maybe a group of 10 participating in actual subject matter-related discussions.

Other e-tutors commented:

Mainly students not being active on the side despite attempts to get them involved. I can do so much more if more students use their e-tutor resources!

The biggest problem is that I find it difficult to get my students to interact. I try to put a "face" to myself by giving them a warm welcome message, encouraging discussion etc. - however I feel they just see me as a remote person.

While there seems to be only a small number of students who participate, there may be many lurkers who peruse the site but do not participate in any activities on the site. These students may still be learning how to use the online platform, and by observing the discussions, their own questions may be answered indirectly.

\section{Misalignment of e-tutor's expectations and institution's expectations}

Many e-tutors commented on the misalignment of expectations between the e-tutor and the institution. Some e-tutors indicated that it was not clear to them what they needed to do or what was expected of them.

At first it was not really clear as to what (we) are supposed to do to engage students in our discussion forums. That took long for us to comprehend and understand.

I am still not sure of the scope of my role and how much I can add to the online environment.

In the beginning it was difficult as I was not very familiar with what our tasks were as etutors and how to go about doing tasks.

Unclear information from administration at the commencement.

The results indicate a lack of communication between the e-tutor and the institution regarding their role and what is expected of them. E-tutors are unsure about their role and may therefore feel vulnerable and lack confidence as an e-tutor. This implies that further training is required prior to beginning e-tutor duties to better orientate and induct them.

\section{Additional training and support}

A third factor mentioned by e-tutors was the need for additional training and support from the coordinators and subject learners.

I am good at one-on-one and group interaction and helping people learn in the "real" world but I don't really know how to get the students to be involved on this platform.

It is clear that these findings support the empirical findings discussed earlier that e-tutors are struggling with the social engagement function. For the majority of e-tutors, it is the first time they have used the online platform. E-tutors may therefore not be confident using this platform and may not be using it as effectively as they should. The results suggest that further training is required to ensure e-tutors make use of the platform effectively. 


\section{Lack of communication}

A large number of e-tutors commented on the lack of communication and feedback from lecturers.

Lack of feedback and communication from lecturers about e-tutor performance.

No regular feedback from admin or lecturer in terms of the communication we do online, if once in a while a feedback can be given wither good or bad, that will go a long way in making this experience effective for our interaction.

I would appreciate feedback from the department regarding my job and/performance.

Lack of practical guidance and feedback on my performance.

Lack of feedback on performance, you can only grow if you know what your mistakes were.

Support from the coordinators and the lecturer of the subject in terms of guidance and always available to assist.

The results above indicate that there needs to be a vast improvement in the communication channels between lecturer and e-tutor. The relationship between the lecturer and e-tutor is crucial as they should be working as a team in order to ensure effective delivery of online learning.

\section{Student preparedness}

Lastly, many e-tutors felt that the students were not prepared for the e-tutor system and commented:

Students are not aware of us and if they are, they do not feel comfortable around us.

New students need to be orientated on the myUnisa platform.

Learners are not properly introduced to e-learning.

Students are not fully engaging with one another on the myUnisa e-tutors' portal, instead students are posting most of their questions on the main module site for the lecturer.

Since the students were all 1st year students, it can be expected that they might not be as comfortable on the online platform as students in the 2nd or 3rd year. Better communication is perhaps required from the institution to communicate to first-time students what the role of the e-tutor is and what is expected of them and their participation on the e-tutor site.

\section{Discussion}

The research highlighted a number of factors that impacted on the effectiveness of the e-tutors. Nonparticipation by students was perceived as the biggest barrier and factor impacting on the effectiveness of the e-tutors. It is perhaps necessary to advise the students at an earlier stage about the role of the e-tutor and to explain to them why they are expected to participate within this environment. Since the e-tutors were all responsible for $1^{\text {st }}$ year modules, a possible reason for the high non-participation rate could be that students are not yet comfortable with the online environment. There may also be a large number of students who are lurkers and peruse the site but do not necessarily post or take part in any of the discussions on the site. Once they become more comfortable with the site, then they might participate more regularly. Salmon (2003) mentions that when participants feel at home with the online culture, and reasonably comfortable with the technology, they move on to contributing.

Another factor impacting on the effectiveness of the e-tutors was the misalignment of expectations between e-tutors and lecturers. E-tutors expressed their frustrations regarding their uncertainties about what is expected of them. To minimise discrepancies between expectations, it is necessary to know the expectations 
that e-tutors have, and their expectations of their own role in their teaching and learning environment. The e-tutors' role needs to be well defined if the expectations of e-tutors, students, and lecturers are to be met. The results of the study suggest that more support is needed in preparing the e-tutors to teach online and create an online community.

The results indicate that e-tutors spend most of their time fulfilling an informative and administrative role. The least amount of time was spent fulfilling the social and pastoral roles, and surprisingly they also found these roles to be the least important. As previously mentioned, the potential reason why students seem reluctant to make use of the e-tutor sites might be that they don't feel comfortable with this new online environment. E-tutors perhaps need to take on a more social and pastoral role in order to provide an appealing environment where students feel safe and cared for. Although e-tutors may have industry experience, they may not necessarily be pedagogical experts. Better pedagogical training might be required so that e-tutors have the skills to lead discussions and answer questions on the electronic discussion boards (Aylward, 2003).

The research highlighted gaps in e-tutors' competencies regarding a number of variables, with the most noteworthy gap representing the social engagement factor. E-tutors perceived it a challenge to engage learners on the online forums. According to Moore (1997), the essential distance in distance education is transactional, not spatial or temporal. It is important to understand what he termed transactional distance theory (TDT), especially in the current move towards an education process by means of technology. Understanding TDT is vital for people to be effective in distance learning and teaching. This means that the transactional distance between learner and e-tutor can be reduced through effective use of communication conventions. It is therefore important to train e-tutors in the effective use of these conventions so that they can reduce the transactional distance between themselves and the students.

Lastly, one has to take into account that the e-tutor system was a new system at the time and therefore one naturally expects to experience teething problems in the first year of implementation. Feedback from both the e-tutors and students is therefore vital in order to ensure the system improves over time.

\section{Implications}

The e-tutor system was implemented as a means to facilitate the learning process for students, through promoting student interaction and student success. The rationale of the e-tutor system is therefore to boost interaction amongst students on the online platform, as well as to encourage engagement with the e-tutor. This is all done in an effort to prevent the student from feeling isolated and an attempt to bridge the distance between student and the university. Ideally the e-tutor system should provide a sense of community, where students can come together and feel part of a larger academic community. This will then ultimately minimise the feeling of detachment that is common amongst open distance learners. Students however need to be convinced of the benefits of such a system so that they participate effectively and reap the benefits.

Currently there is no incentivised structure incorporated into the e-tutor model. In order to change the actual participation level of students, it is recommended that an incentivised approach be used, where meaningful contributions to the discussion forum are integrated into formative assessment. This should motivate the students to learn how to participate in online discussion forums and teach them to think critically about the contributions they make. Furthermore, if the e-tutors respond to questions posed timeously, it should create the feeling that help is at hand and increase the sense of support from e-tutors.

Distance learners often experience a feeling of isolation and lack of confidence in terms of learning. This is particularly true for first time students, who are experiencing an online platform for the first time. Here, e-tutors can play a crucial role in inducting students to this type of platform, and providing a face to the university. E-tutors have the ability to provide a friendly and comfortable social environment in which students feel that learning is possible (McPherson \& Nunes, 2004). The results of the study however indicate that more support is needed in preparing the e-tutors to teach online and create an online community. The university should perhaps look into additional support for e-tutors by having them work with a group or team of different experts such as online facilitators, developers, and instructional designers. 
The participants in this study were e-tutors employed on a part-time basis on temporary contracts. When tutoring is outsourced to casual staff, tutors themselves may feel detached from the university and the permanent staff. They also do not have input in course design, and this impacts on the tutors' sense of professional identity and agency (Tait, 2004). In such a situation it becomes crucial that teaching staff who are experienced in online learning take a more proactive role in assisting e-tutors to become effective etutors. The findings of this study imply that e-tutors require continuous online skills training, along with mentoring and coaching from the subject head. Ongoing mentoring by the experienced subject head, should take place to assist tutors to put into practice the requirements of an e-tutors' role. The subject head needs to encourage e-tutors to employ best practices for online delivery, by setting an example of how online engagement and support should be managed. A particular request by e-tutors was for periodic feedback regarding aspects of their job which implies the need for better communication between the e-tutor and the subject head. The lecturer could, for example, provide feedback sessions at the end of every quarter or provide a platform for e-tutors to provide suggestions or best-case scenarios.

The university needs to take measures to improve the relationship between the tutors and the university in general; as well as between the tutors and the subject head. The study highlighted that the e-tutor roles were not communicated effectively with the e-tutors as it was not implicitly clear to them what was expected of them. The subject head's perceptions of the roles they expect the e-tutors to play may differ from module to module; understanding what subject leaders expect from their e-tutors is crucial in ensuring a good working relationship. In addition, it is important to ensure that there is a sense of community amongst the e-tutors, so that they feel part of a larger group, as opposed to isolated individuals. Additional $e$-tutor socials could be arranged to provide e-tutors the opportunity to meet each other and their subject heads, and learn from each other.

This study highlighted the importance of the social/pastoral role and therefore it is recommended that etutors be coached on the nature of successful online interaction with students. These interactions may for example teach e-tutors how to create a welcoming environment, how to interact in a warm and engaging manner and provide the social support students need. Goold et al., (2010) contend that novice e-tutors, in particular need to be guided and trained to direct students' online communication and collaboration in ways that will ensure that learning objectives are being met. Online environments are continuously evolving, and therefore the provision of professional development for both academic staff and e-tutors are required on a continuous basis as the online learning system develops and changes (Goold et al., 2010).

\section{Limitations and future research}

This study focussed on the importance of certain roles and competencies of e-tutors at an ODL learning institution. However, during the study the importance of the social and pastoral role of the e-tutor emerged and this raised new questions. It seems plausible that the learners have a stronger need to feel they form part of a group and yet are receiving personal support, than what the traditional system could offer. An indepth study of how these roles can be internalised by the e-tutors and used to improve the engagement of learners in the e-tutor system, should receive further research attention. An improved understanding of the implementation of these roles may assist the university to make the students feel at home in the online environment and improve participation of students in the e-tutor platform. The ultimate goal of the university, namely improved student throughput and success, should benefit from such an understanding.

This study only focused on e-tutors perceptions and reflection on their roles and competences. As indicated earlier in this article, the research presented in this article is part of a larger study. The researchers aim to extend this research, with a second and third phase. The second phase will investigate student's perception about their expectations and how they perceive the role of the e-tutor to be. Understanding both students and e-tutors perceptions of their roles and expectations may prevent confusion or an unrealistic expectation of what is expected from each party. The third phase will determine the positive psychological functioning (PsyCap) of the e-tutors and the effect of their psychological functioning on their work experience.

The role of the e-tutor for this study only allows for asynchronous communication, this involves delayed communication between the student and e-tutor. Csikszentmihalyi (2003) warns that the nature of asynchronicity makes it harder to create positive group experiences as it affects the excitement, rhythm, engagement, and flow of the experience. Further research is required to assess the need for the use of synchronous versus asynchronous communication. Lastly, student's proficiency with information 
communications technology (ICT) has a notable impact on levels of online activity (Packham et al., 2004). Future research is required to assess how proficient students are with the online management system, as this may be a contributing factor for the low levels of participation currently experienced by e-tutors.

In conclusion, the research that was carried out amongst the e-tutors was aimed at bringing to the fore the needs of e-tutors and provided a platform for them to be heard. The results provided some valuable feedback, highlighting the need to get students more involved on the online platform and ensuring that they are prepared for the e-tutoring environment. The results further highlighted the different roles that are important to the e-tutor and how competent they felt in each role. It is evident that e-tutors play a crucial role in e-learning, particularly since they are first and foremost the face of the university and often the first point of contact for the students. The process of online tutoring therefore becomes a critical success factor in learner acceptance of e-learning. E-tutors are also strategically important for the perception of the quality and attractiveness of the university. Such an investigation is therefore necessary as e-tutors need to be equipped with the appropriate skills and competencies to be effective in the online environment.

\section{References}

Aylward, L. (2003). Construction or Confucianism? We have the technology, now what shall we do with it? In A. Tait, \& R. Mills (Eds.). Rethinking learner support in distance education: Change and continuity in an international context. (pp. 3-13). London: Routledge Falmer.

Baronov, D. (2012). Conceptual foundations of social research methods. (2nd ed.). London: Boulders.

Bates, T. (2008). Transforming distance education through new technologies. In T. Evan, M. Haughey, \& D. Murphy (Eds.) International handbook of distance education. Bingley: Emerald Group.

Baumann, U., Shelley, M., Murphy, L., \& White, C. (2008). New challenges, the role of the tutor in the teaching of languages at a distance. Distances et saviors, 6(3), 365-392. https://doi.org/10.3166/ds.6.365-392

Bennet, S., \& Marsh, D. (2002). Are we expecting online tutors to run before they can walk? Innovations in Education and Teaching International, 39(1), 14-20. https://doi.org/10.1080/13558000110097055

Berge, Z. L. (1995). Facilitating computer conferencing: Recommendations from the field. Educational Technology, 35(1), 22-30.

Biddle, B. J. (1986). Recent developments in role theory. Annual Review of Sociology, 12(1), 67-92. https://doi.org/10.1146/annurev.so.12.080186.000435

Brown, C. (2002). Simple and effective - Teacher roles remain a powerful framework to embed ICT within the practice of teaching. In D. Willis, J. Price, \& N. Davis (Eds), Proceedings of SITE 2002 Society for Information Technology and Teacher Education International Conference, Nashville, TN. Retrieved from https://www.learntechlib.org/p/10699/

Chang, C., Shen, H., \& Liu, E. Z. (2014). University faculties' perspectives on the roles of e-instructors and their online instruction practice. International Review of Research in Open and Distance Learning, 15(3), 72-92. http://dx.doi.org/10.19173/irrodl.v15i3.1654

Collins, M. P. \& Berge, Z. L. (1997, March). Moderating online electronic discussion groups. Paper presented at the American Educational Research Association Conference, Chicago. Retrieved from http://emoderators.com/wp-content/uploads/aera97c.html

Cox, E. S., Clark, W. P., Heath, H., \& Plumpton, B. (2000). Key facilitation skills for effective online discussion groups: Herding cats through Piccadilly Circus. Proceedings from Distance Education: An open question, Adelaide. Retrieved from http://www.com.unisa.edu.au/cccc/papers/refereed/paper11/Paper11-1.htm

Csikszentmihalyi, M. (2003). Good business: Leadership, flow and the making of meaning. New York, NY: Penguin Books.

Denis, B., Watland, P., Pirotte, S., \& Verday, N. (2004). Roles and competencies of the e-Tutor. Proceedings of the Networked Learning Conference, Lancaster. Retrieved from https://orbi.ulg.ac.be/bitstream/2268/12722/1/DENIS_WATLAND_PIROTTE_VERDAY_Roles and competencies of the tutor_30_03_2009.pdf

Field, A. (2005). Discovering statistics using SPSS (2nd ed.). London: Sage.

Gibson-Harman, K., Rodriguez, S., \& Haworth, JG. (2002). Community college faculty and professional staff: The human resource challenge. New Directions for Community Colleges, 117, 77-90. http://doi.org/10.1002/cc.55 
Goodyear, P., Salmon, G., Spector, M. J., Steeples, C., \& Tickner, S. (2001). Competences for online teaching: a special report. Educational Technology Research and Development, 49(1), 65-72. https://doi.org/10.1007/BF02504508

Goold, A., Coldwell, J., \& Craig, A. (2010). An examination of the role of the e-tutor. Australasian Journal of Educational Technology, 26(5), 704-716. https://doi.org/10.14742/ajet.1060

Jelfs, A., Richardson, J. T. E., \& Price, L. (2009). Student and tutor perceptions of effective tutoring in distance education. Distance Education, 30(3), 419-441. https://doi.org/10.1080/01587910903236551

Lentell, H. (2003). The importance of the tutor in open and distance learning. In A. Tait, \& R. Mills (Eds.). Rethinking learner-support in distance education (pp. 64-76). London: Routledge Falmer.

Lentell, H., \& O’Rourke, J. (2004). Tutoring large numbers: An unmet challenge. International Review of Research in Open and Distance Learning, 5(1), 1-17. Retrieved from http://www.irrodl.org/index.php/irrodl/article/view/171/253

Lovelock, C., Patterson, P. G., \& Walker, R. H. (1998). Service marketing. Sydney: Prentice-Hall.

Makoe, M. (2011). Academics going mobile: New roles for new technologies. Progressio, 33(2), 174188. Retrieved from http://0-hdl.handle.net.oasis.unisa.ac.za/10520/EJC119669

Mashile, O. (2012). Unisa tutor model. Report compiled for Senate Teaching and Learning Committee, March 2012. Pretoria: University of South Africa.

McMann, G. W. (1994). The changing role of moderation in computer mediated conferencing. Proceedings of the Distance Learning Research Conference, San Antonio, TX. 159-166.

McPherson, M., \& Nunes, M. B. (2004). The role of tutors as an integral part of online learning support. Retrieved from http://www.eurodl.org/materials/contrib/2004/Maggie_MsP.html

McShane, K. (2000). The online academic: Case study narratives of change and resistance. Proceedings of Ascilite Conference, Coffs Harbour. Retrieved from http://www.ascilite.org/conferences/coffs00/papers/kim_mcshane.pdf

Moore, M. G. (1997). The theory of transactional distance. In M. G. Moore (Ed.), The handbook of distance education (2nd ed., pp. 89-108). Mahwah, NJ: Lawrence Erlbaum.

O’Neil, T. (2009). How distance education has changed teaching and the role of the instructor. Information Systems Education Journal, 7(48), 1-11. Retrieved from http://www.isedj.org/7/48/ISEDJ.7(48).ONeil.pdf

Open Distance Learning Task Team 4. (2010). Conceptual framework for student support at Unisa. Pretoria: University of South Africa.

Packham, G., Cramphorn, C., \& Miller, C. (2001). Module development through peer-assisted student support: An initial evaluation. Mentoring and Tutoring, 9(2), 113-124. https://doi.org/10.1080/13611260123245

Packham, G., Jones, P., Miller, C., \& Thomas, B. (2004). Perceptions of effective e-moderation: A tutor's viewpoint. Proceedings of the Networked Learning Conference, Lancaster University, 504511.Pallant, J. (2013). SPSS survival manual: A step by step guide to data analysis using IBM SPSS (4th ed.). Crows Nest: Allen \& Unwin.

Perraton, H., Creed, C., \& Robinson, B. (2002). Teacher education guidelines: Using open and distance learning. Retrieved from http://unesdoc.unesco.org/images/0012/001253/125396e.pdf

Salmon, G. (2003). E-moderating: The key to teaching and learning online. London: Routledge Falmer.

Savory, J. R. (2005). Be vocal: Characteristics of successful online instructors. Journal of Interactive Online Learning, 4(2), 141-152.

Spector, J. M., \& De la Teja, I. (2001). Competencies for online teaching. Retrieved from http://files.eric.ed.gov/fulltext/ED456841.pdf

Tabachnick, B. G., \& Fidell, L. S. (2007). Using multivariate statistics (5th ed.). Boston, MA: Allyn \& Bacon.

Tait, A. (2004). The tutor/facilitator role in student retention Open Learning, 19(1), 97-109. https://doi.org/10.1080/0268051042000177872

Varvel, V. (2007). Master online teacher competences. Online Journal of Distance Learning Administration, 10(1). Retrieved from http://www.westga.edu/ distance/ojdla/spring101/varvel101.htm. Accessed 24 July 2013.

Williams, C. (2002). Learning online: A review of recent literature in a rapidly expanding field. Journal of Further and Higher Education, 26(2), 263-72. https://doi.org/10.1080/03098770220149620

University of South Africa (2013). Online independent contractors: Online tutors. Retrieved from http://www.unisa.ac.za/vacancies_view/html/5490.htm 
University of South Africa (2007). Unisa ethics policy. Retrieved from http://www.unisa.ac.za/contents/colleges/col_agriculture_environ_sciences/docs/ResearchEthicsPolic yJan2013.pdf

Corresponding author: Nadine de Metz, dmetzn@unisa.ac.za

Australasian Journal of Educational Technology (c) 2017.

Please cite as: Author, A., \& Author, B. (2017). An importance-competence analysis of the roles and competencies of e-tutors at an open distance learning institution. Australasian Journal of Educational Technology, 34(5), 27-43. https://doi.org/10.14742/ajet.3364 